\title{
A high dietary concentration of inulin is necessary to reduce the incidence of swine dysentery in pigs experimentally challenged with Brachyspira hyodysenteriae
}

\author{
Christian F. Hansen ${ }^{1,2}$, Aracely Hernández ${ }^{1}$, Josie Mansfield ${ }^{1}$, Álvaro Hidalgo ${ }^{3}$, Tom La ${ }^{1}$, \\ Nyree D. Phillips ${ }^{1}$, David J. Hampson ${ }^{1}$ and John R. Pluske ${ }^{1 *}$ \\ ${ }^{1}$ Animal Research Institute, School of Veterinary and Biomedical Sciences, Murdoch University, Murdoch, WA 6150, \\ Australia \\ ${ }^{2}$ Department of Large Animal Science, Faculty of Life Sciences, University of Copenhagen, Groennegaardsvej 2, \\ 1870 Frederiksberg C, Denmark \\ ${ }^{3}$ Department of Animal Health, Faculty of Veterinary Science, University of León, León 24071, Spain
}

(Received 29 October 2010 - Revised 14 March 2011 - Accepted 14 March 2011 - First published online 7 June 2011)

\begin{abstract}
A total of sixty surgically castrated male pigs (Large White $\times$ Landrace) weighing $31 \cdot 2(\mathrm{sD} 4 \cdot 3) \mathrm{kg}$ were used in a randomised block experiment to examine the effect of added dietary inulin $(0,20,40$ and $80 \mathrm{~g} / \mathrm{kg})$ on the occurrence of swine dysentery (SD) and on fermentation characteristics in the large intestine after experimental challenge with the causative spirochaete Brachyspira byodysenteriae. The pigs were allowed to adapt to the diets for 2 weeks before each pig was challenged orally four times with a broth culture containing $B$. hyodysenteriae on consecutive days. Increasing dietary levels of inulin linearly $(P=0 \cdot 001)$ reduced the risk of pigs developing SD; however, eight out of fifteen pigs fed the diet with $80 \mathrm{~g} / \mathrm{kg}$ inulin still developed the disease. The $\mathrm{pH}$ values in the caecum $(P=0 \cdot 072)$ tended to decrease, and in the upper colon, the $\mathrm{pH}$ values did decrease $(P=0.047)$ linearly with increasing inulin levels in the diets, most probably due to a linear increase in the concentration of total volatile fatty acids in the caecum $(P=0 \cdot 018)$, upper colon $(P=0.001)$ and lower colon $(P=0.013)$. In addition, there was a linear reduction in the proportion of the branched-chain fatty acids isobutyric acid and isovaleric acid in the caecum $(P=0.015$ and 0.026$)$ and upper colon $(P=0.011$ and 0.013$)$ with increasing levels of dietary inulin. In conclusion, the present study showed that a diet supplemented with a high level of inulin ( $80 \mathrm{~g} / \mathrm{kg}) \mathrm{but}$ not lower levels reduced the risk of pigs developing SD, possibly acting through a modification of the microbial fermentation patterns in the large intestine.
\end{abstract}

Key words: Brachyspira hyodysenteriae: Inulin: Pigs: Swine dysentery

Swine dysentery (SD) is a contagious mucohaemorrhagic diarrhoeal disease that mainly occurs in pigs in the grower/ finisher phase. The essential causative agent of SD is the anaerobic intestinal spirochaete Brachyspira byodysenteriae, and this pathogen acts in association with other anaerobic members of the large-intestinal microbiota to induce extensive inflammation and necrosis of the epithelial surface of the caecum and colon ${ }^{(1)}$. It is known that the pigs' diet can have a strong influence on colonisation by $B$. hyodysenteriae and on the occurrence of clinical signs of SD. Several studies have been undertaken to elucidate the effects of different types of carbohydrates on colonisation with B. hyodysenteriae and on the incidence of SD, but the results have been contradictory $^{(2-5)}$. Recently, a diet containing chicory root and sweet lupin was shown to offer protection against $\mathrm{SD}^{(6)}$, and subsequently we demonstrated that feeding pigs $80 \mathrm{~g} / \mathrm{kg}$ inulin but not lupin prevented SD following experimental challenge with $B$. byodysenteriae ${ }^{(7)}$. Inulin is a mildly sweet, white polysaccharide that is normally extracted from chicory root.

Physiologically, fructo-oligosaccharides such as inulin are classified as dietary fibre and are resistant to complete enzymatic degradation in the small intestine. Undigested fibre entering the caecum and colon functions as a substrate for fermentative processes and generates a higher luminal concentration of volatile fatty acids (VFA), which in turn can cause lower luminal $\mathrm{pH}$ values ${ }^{(8)}$. Inulin is mainly fermented in the large intestine to VFA, lactate and gas by Bifidobacteria and Lactobacilli species ${ }^{(9)}$. In addition, dietary inulin supplementation may regulate metabolic activity, decreasing the

Abbreviations: BCFA, branched-chain fatty acids; $\mathrm{N}-\mathrm{NH}_{3}, \mathrm{NH}_{3}$ nitrogen; $\mathrm{SD}$, swine dysentery; VFA, volatile fatty acids. 
protein:carbohydrate ratio in the hindgut. As a result, carbohydrate fermentation may suppress the formation of branched-chain fatty acids (BCFA) and $\mathrm{NH}_{3}$ produced from protein fermentation $^{(10)}$

Dietary supplementation with inulin is expensive, and currently no information is available concerning the level of dietary inulin inclusion that is necessary to reduce the occurrence of SD and cause changes in the microbiota in the large intestine of pigs. Accordingly, the present study was designed to determine whether dietary inclusion of less than $80 \mathrm{~g} / \mathrm{kg}$ inulin could prevent pigs that were experimentally challenged with $B$. byodysenteriae from developing the disease. The hypothesis tested was that a diet supplemented with $80 \mathrm{~g} / \mathrm{kg}$ inulin would decrease the risk of pigs developing SD and reduce protein fermentation in the hindgut.

\section{Materials and methods}

The present study was conducted with the approval of the Murdoch University Animal Ethics Committee (R2186-08). Animals were cared for according to the Australian Code of Practice for the Care and Use of Animals for Scientific Purposes ${ }^{(11)}$.

\section{Animals and housing}

A total of sixty surgically castrated commercial pigs (Large White $\times$ Landrace) were obtained at weaning from a commercial specific-pathogen-free piggery known to be free of SD. At weaning, the pigs were housed in a group at Murdoch University and were offered the same commercially formulated diets without any feed additives or antimicrobial compounds until they reached a body weight of 31.2 (SD $4.28) \mathrm{kg}$. At this time, the pigs were allocated to one of the four experimental diets based on their body weight. The pigs were housed in a temperature-controlled animal house in three identical rooms. Each room had four pens in a square arrangement so that each pen was adjacent to two other pens. The pens were raised above the ground and had fully slatted plastic floors and wire mesh sides that allowed contact between the animals and passage of manure between the pens. In each room, there was one pen of five pigs per experimental diet (i.e. there were fifteen pigs per experimental diet). Each pen was equipped with a dry-feed single space feeder without water and two drinking bowls. Throughout the study, the pigs had ad libitum access to feed and water. Group housing was chosen to facilitate transmission of the pathogenic bacteria within and between groups $^{(4,7,12)}$. The pigs were allowed to adapt to the diets for 2 weeks before being challenged with B. byodysenteriae.

\section{Experimental design and diets}

The experimental design was a completely randomised block arrangement, with four dietary treatments differing in the amount of added dietary inulin $(0,20,40$ and $80 \mathrm{~g} / \mathrm{kg})$. The four diets were formulated, as shown in Table 1 , to meet or exceed the nutrient requirements for pigs of this genotype, and all diets contained the same energy and protein (amino acids) contents. Inulin (Orafti ${ }^{\circledR} \mathrm{ST}$; Orafti, Tienen, Belgium) was added to the diets at the expense of triticale and barley. The diets were produced in mash form using the same batch of raw materials and did not contain any antimicrobials.

\section{Challenge with Brachyspira hyodysenteriae and assessment of swine dysentery}

Australian B. byodysenteriae strains WA1 and B/Q02 were obtained as frozen stocks from the culture collection at the Reference Centre for Intestinal Spirochaetes, Murdoch University. They were thawed and grown in Kunkle's pre-reduced anaerobic broth containing $2 \%(\mathrm{v} / \mathrm{v})$ fetal bovine serum and $1 \%(\mathrm{v} / \mathrm{v})$ ethanolic cholesterol solution ${ }^{(13)}$, and were incubated at $37^{\circ} \mathrm{C}$ on a rocking platform until early log-phase growth was achieved.

Each morning for four consecutive days, all pigs were challenged via a stomach tube with $100 \mathrm{ml}$ broth culture containing approximately $10^{9}$ colony-forming units $/ \mathrm{ml}$ of B. byodysenteriae, made up of equal numbers of each of the two spirochaete strains. At this time, the pigs had an average body weight of $41 \cdot 1$ (SD $4 \cdot 47) \mathrm{kg}$.

The pigs were weighed weekly, and rectal swabs were taken from all pigs twice a week for spirochaete culture. Visual faecal consistency scoring (1, firm, well formed; 2, soft; 3, loose; 4, watery; 5, watery with mucus/blood) was conducted daily. Watery diarrhoea with mucus/blood was considered as indicating SD, and pigs showing these signs were removed for post-mortem examination within $48 \mathrm{~h}$. All other pigs were removed for necropsy $42 \mathrm{~d}$ after the first day of challenge.

\section{Post-mortem}

Euthanasia was by captive bolt stunning followed by exsanguination. The gastrointestinal tract was removed immediately and divided into seven segments by ligatures: stomach, duodenum, jejunum, ileum, caecum, upper colon and lower colon. The presence, distribution and nature of gross lesions in the large intestine were recorded ${ }^{(14)}$, and bacteriological swabs were taken from the wall of the caecum and proximal colon for spirochaetal culture. The luminal contents were then removed by gently squeezing the material from the gut segment. The empty segments and collected material were weighed, and representative samples were collected in sterile plastic tubes that were snap-frozen in liquid $\mathrm{N}_{2}$ within $10 \mathrm{~min}$ of euthanasia. Samples for DM and VFA examination were stored at $-20^{\circ} \mathrm{C}$ until analysis.

For determination of $\mathrm{NH}_{3}$ nitrogen $\left(\mathrm{N}-\mathrm{NH}_{3}\right)$, digesta samples were diluted 1:1 (w/v) with TCA (10\%), mixed, snap-frozen in liquid $\mathrm{N}_{2}$ and stored at $-80^{\circ} \mathrm{C}$ until analysis. The $\mathrm{pH}$ values of the digesta were measured by inserting the electrode of a calibrated portable $\mathrm{pH}$ meter (Schindengen pH Boy-2; Schindengen Electric MFG, Tokyo, Japan) into the collected sample. The DM content of samples was measured using the AOAC method $(930.15)^{(15)}$. 
Table 1. Diet ingredients and chemical composition of the experimental diets

\begin{tabular}{lcccc}
\hline Inulin (g/kg)... & 0 & 20 & 40 & 80 \\
\hline Ingredient (g/kg as-fed) & & & & \\
Triticale & $400 \cdot 3$ & $390 \cdot 2$ & $379 \cdot 9$ & $359 \cdot 2$ \\
Barley & $306 \cdot 1$ & $288 \cdot 0$ & $270 \cdot 0$ & $234 \cdot 1$ \\
Rapeseed meal & $185 \cdot 0$ & $185 \cdot 0$ & $185 \cdot 0$ & $185 \cdot 0$ \\
Soyabean meal, 48\% & $76 \cdot 5$ & $85 \cdot 1$ & $93 \cdot 5$ & $110 \cdot 4$ \\
Inulin* & - & $20 \cdot 0$ & $40 \cdot 0$ & $80 \cdot 0$ \\
Rapeseed oil & $10 \cdot 0$ & $10 \cdot 0$ & $10 \cdot 0$ & $10 \cdot 0$ \\
Limestone & $10 \cdot 3$ & $10 \cdot 1$ & $9 \cdot 9$ & $9 \cdot 5$ \\
Dicalcium phosphate & $5 \cdot 6$ & $5 \cdot 8$ & $6 \cdot 0$ & $6 \cdot 4$ \\
Salt & $3 \cdot 5$ & $3 \cdot 5$ & $3 \cdot 5$ & $3 \cdot 5$ \\
L-Lys & $1 \cdot 6$ & $1 \cdot 4$ & $1 \cdot 2$ & $0 \cdot 8$ \\
Vitamin/mineral premix† & $1 \cdot 0$ & $1 \cdot 0$ & $1 \cdot 0$ & $1 \cdot 0$ \\
Calculated composition & & & & \\
PPE (MJ/kg) & $7 \cdot 9$ & $7 \cdot 9$ & $7 \cdot 9$ & $7 \cdot 9$ \\
SID crude protein (g/MJ PPE) & $17 \cdot 6$ & $17 \cdot 6$ & $17 \cdot 6$ & $17 \cdot 6$ \\
SID lysine (g/MJ PPE) & $1 \cdot 00$ & $1 \cdot 00$ & $1 \cdot 00$ & $1 \cdot 00$ \\
Crude protein (g/kg) & 173 & 175 & 176 & 179 \\
Crude fat (g/kg) & $39 \cdot 3$ & $38 \cdot 9$ & $38 \cdot 4$ & $37 \cdot 6$ \\
Analysed composition & & & & \\
Crude protein (g/kg) & 183 & 185 & 183 & 188 \\
Crude fat (g/kg) & 48 & 49 & 42 & 47 \\
Calculated carbohydrate composition (g/kg DM) & & & & \\
Glucose, sucrose and fructose & 42 & 43 & 44 & 46 \\
Fructans (inulin) & 7 & 25 & 44 & 81 \\
Cellulose & 36 & 35 & 35 & 34 \\
Soluble NCP & 34 & 33 & 33 & 32 \\
Insoluble NCP & 92 & 90 & 88 & 85 \\
NCP & 126 & 123 & 121 & 116 \\
NSP (cellulose + NCP) & 162 & 159 & 156 & 150 \\
Klason lignin & 37 & 36 & 36 & 35 \\
Dietary fibre (NSP + lignin) & 199 & 195 & 192 & 185 \\
\hline
\end{tabular}

PPE, potential physiological energy; SID, standardised ileal digestible; NCP, non-cellulosic polysaccharides. ${ }^{*}$ Orafti ${ }^{\circledR} \mathrm{ST}$, Orafti, Tienen, Belgium.

† Supplied/kg of diet: $\mathrm{Fe}\left(\mathrm{FeSO}_{4}\right), 60.0 \mathrm{mg} ; \mathrm{Cu}\left(\mathrm{CuSO}_{4}\right), 10.0 \mathrm{mg} ; \mathrm{Mn}(\mathrm{MnO}), 40.0 \mathrm{mg} ; \mathrm{Zn}(\mathrm{ZnO}), 100.0 \mathrm{mg} ; \mathrm{Se}$ $\left(\mathrm{Na}_{2} \mathrm{SeO}_{3}\right), 0.30 \mathrm{mg} ; \mathrm{I}(\mathrm{KI}), 0.50 \mathrm{mg}$; Co $\left(\mathrm{CoSO}_{4}\right), 0.20 \mathrm{mg}$; vitamin A, $7000 \mathrm{IU}(2100 \mu \mathrm{g})$; vitamin $\mathrm{D}_{3}, 1400 \mathrm{IU}$ $(35 \mu \mathrm{g})$; vitamin E, $20.0 \mathrm{mg}$; vitamin $\mathrm{K}_{3}, 1.0 \mathrm{mg}$; thiamin, $1.0 \mathrm{mg}$; riboflavin, $3.0 \mathrm{mg}$; pyridoxine, $1.5 \mathrm{mg}$; vitamin $\mathrm{B}_{12}, 0.015 \mathrm{mg}$; pantothenic acid, $10.0 \mathrm{mg}$; folic acid, $0.2 \mathrm{mg}$; niacin, $12.0 \mathrm{mg}$; biotin, $0.03 \mathrm{mg}$. $\ddagger$ Potential physiological energy ${ }^{(35)}$.

\section{Histological measurements}

A ring-like cross-section of the ileum was collected and immediately fixed in $10 \%$ neutral-buffered formalin. Measurements of villous height and crypt depth were conducted as described by Hansen et al. ${ }^{(7)}$.

\section{Bacteriological analysis}

Bacteriological swabs taken from faeces, caecum and colon were streaked onto selective agar plates designed for isolation of Brachyspira species ${ }^{(16)}$, consisting of Trypticase Soya agar (Becton Dickinson Microbiology Systems, Cockeysville, MD, USA) containing 5\% (v/v) defibrinated sheep blood, spectinomycin $(400 \mu \mathrm{g} / \mathrm{ml})$, and colistin and vancomycin (each $25 \mu \mathrm{g} / \mathrm{ml}$ ) (Sigma, St Louis, MO, USA). The plates were incubated for $5-7 \mathrm{~d}$ at $37^{\circ} \mathrm{C}$ in a jar with an anaerobic environment generated using a GasPak Plus disposable $\mathrm{H}_{2}+\mathrm{CO}_{2}$ generator envelope with a Pd catalyst (Becton Dickinson Microbiology Systems, Franklin Lakes, NJ, USA). The presence of low, flat, spreading growth of spirochaetes on the plate and any haemolysis around the growth were recorded. Spirochaetes were confirmed by selecting areas of suspected growth, resuspending in PBS and examining the suspension under a phase-contrast microscope at $400 \times$ magnification. Spirochaetes were identified as B. byodysenteriae on the basis of strong $\beta$-haemolysis, microscopic morphology and PCR results of an NADH oxidase gene for cell growth on the plates. The PCR primers and conditions have been described previously ${ }^{(17)}$.

\section{Analysis of feed, organic acids and ammonia nitrogen}

The $\mathrm{N}$ content of the feed was determined with a $\mathrm{N}$ analyser (LECO FP-428; LECO Corporation, St Joseph, MI, USA) by a combustion method (American Organization of Analytical Chemists 990.03) ${ }^{(15)}$. Crude protein was calculated by multiplying the $\mathrm{N}$ content by $6 \cdot 25$. Crude fat was measured using the AOAC Soxhlet method $(960.39)^{(15)}$.

The concentrations of organic acids (formic acid, VFA, lactic acid and succinic acid) in the ileal contents were analysed by the method described by Jensen et al. ${ }^{(18)}$. The VFA concentrations in caecal and colon contents were determined as described by Heo et al. ${ }^{(19)}$.

Concentrations of $\mathrm{N}^{-\mathrm{NH}_{3}}$ were measured according to the method by Weatherburn ${ }^{(20)}$. Briefly, the supernatant was 
deproteinised using $10 \%$ TCA. $\mathrm{NH}_{3}$ and phenol were oxidised by sodium hypochlorite in the presence of sodium nitroprusside to form a blue complex. The intensity was measured colorimetrically at a wavelength of $623 \mathrm{~nm}$. Intensity of the blue colour is proportional to the concentration of $\mathrm{NH}_{3}$ present in the sample.

\section{Statistical analysis}

All statistical analyses were performed using SAS (version 9.2; SAS Institute, Inc., Cary, NC, USA), with each pig regarded as the experimental unit, given that each pig was challenged. A binary response was recorded for each pig with respect to colonisation with $B$. byodysenteriae. Data were analysed with a logistic regression model using the GENMOD procedure in SAS, with the effect of inulin and room as fixed effects. The Pearson $\chi^{2}$ correction (pscale) was applied to correct for overdispersion.

The effect of inulin inclusion on the various quantitative variables measured was analysed univariately by the generalised linear model (GLM) procedure of SAS, with room and dietary inulin level included in the model. Polynomial regression was used to determine the presence of linear or quadratic treatment effects as inulin levels were increased. Pearson's correlation coefficients $(r)$ between digesta $\mathrm{pH}$ and concentrations of VFA were calculated using the CORR procedure. Statistical significance was accepted at $P<0.05$, and $P<0 \cdot 10$ was considered a trend.

\section{Results}

Overall, there was a good general correspondence between the expected and analysed contents of nutrients in the experimental diets (Table 1).

\section{Incidence of swine dysentery and re-isolation of} Brachyspira hyodysenteriae

The incidence of SD and isolation of B. byodysenteriae from faeces and colonic digesta are shown in Table 2. Pigs fed 0, 20 and $40 \mathrm{~g} / \mathrm{kg}$ inulin generally had a greater risk $(P=0.002)$ of developing SD and were more likely $(P<0 \cdot 001)$ to have colonic contents that were culture positive for $B$. byodysenteriae at kill compared with pigs receiving $80 \mathrm{~g} / \mathrm{kg}$ inulin. Although pigs fed $80 \mathrm{~g} / \mathrm{kg}$ inulin were less likely to have faecal samples that were culture positive for $B$. byodysenteriae during the experimental period, eight out of fifteen did develop the disease.

\section{DM, pH and ammonia nitrogen}

The DM content in the caecum decreased linearly $(P=0 \cdot 007)$ with increasing dietary inulin levels (Table 3 ). The opposite occurred in the lower colon, with the DM content increasing linearly $(P=0.007)$ with increasing inulin levels. The DM content in the ileum and upper colon were not influenced by diet.

The $\mathrm{pH}$ values in the caecum tended to decrease $(P=0.072)$ and in the upper colon decreased $(P=0.047)$ linearly with inulin levels in the diets. In the ileum and lower colon, the $\mathrm{pH}$ values were not influenced by diet. $\mathrm{N}-\mathrm{NH}_{3}$ concentrations in the caecum, upper colon and lower colon were unaffected by dietary inulin levels (Table 3).

\section{Organic acids in digesta}

Diet did not affect the total concentration of organic acids or the molar proportion of the organic acids in the ileum, except for a tendency towards a linear decrease in the proportion of propionic acid ( $P=0.060$; Table 4$)$. On the other hand, a linear increase in total VFA concentration was observed in the caecum $(P=0 \cdot 018)$, upper colon $(P=0 \cdot 001)$ and lower colon $(P=0 \cdot 013)$. In the caecum, increasing dietary inulin tended to linearly increase the molar proportion of propionic acid $(P=0.067)$, whereas a linear reduction in the percentage of isobutyric acid $(P=0.015)$ and isovaleric acid $(P=0.026)$ was observed. In the upper colon, there was a linear decrease, or there tended to be a decrease, in the percentage of acetic acid $(P=0.065)$, isobutyric acid $(P=0.011)$ and isovaleric acid $(P=0.013)$ with increasing levels of dietary inulin. In contrast, an increase or tendency towards a linear increase was found for propionic acid $(P=0.038)$, butyric acid $(P=0.070)$ and valeric acid $(P=0.007)$. In the upper colon, there was a linear increase in the percentage of butyric acid $(P=0.026)$, valeric acid $(P=0.005)$ and caproic acid $(P=0 \cdot 051)$, but a tendency towards a linear decrease in the proportion of isobutyric acid $(P=0.056)$.

Overall, total VFA concentrations and $\mathrm{pH}$ in digesta were negatively correlated in the ileum (Pearson's $r=-0 \cdot 29$;

Table 2. Number of positive pigs and relative risk* of a pig being culture positive for Brachyspira hyodysenteriae or showing clinical signs of swine dysentery (fifteen pigs per dietary treatment)

\begin{tabular}{|c|c|c|c|c|c|c|}
\hline \multirow[b]{2}{*}{ Inulin $(\mathrm{g} / \mathrm{kg}) \ldots$} & \multirow[b]{2}{*}{0} & \multirow[b]{2}{*}{20} & \multirow[b]{2}{*}{40} & \multirow[b]{2}{*}{80} & \multicolumn{2}{|c|}{$P$} \\
\hline & & & & & Inulin & Linear \\
\hline Pigs challenged & 15 & 15 & 15 & 15 & & \\
\hline Pigs with clinical swine dysentery & 15 & 14 & 13 & 8 & & \\
\hline Relative risk of clinical swine dysentery & 1.9 & 1.8 & 1.6 & 1.0 & 0.022 & 0.001 \\
\hline Pigs shedding $B$. hyodysenteriae in faeces (culture) & 15 & 15 & 14 & 11 & & \\
\hline Relative risk of culture positive $B$. hyodysenteriae faeces & 1.4 & 1.4 & $1 \cdot 3$ & 1.0 & $<0.001$ & $<0.001$ \\
\hline Pigs with culture positive $B$. hyodysenteriae colon content at euthanasia & 15 & 15 & 13 & 10 & & \\
\hline Relative risk of culture positive $B$. hyodysenteriae colon content at euthanasia & 1.5 & 1.5 & 1.3 & 1.0 & $<0.001$ & $<0.001$ \\
\hline
\end{tabular}

${ }^{*}$ The risk of an event in the group of interest compared with the reference group. 
Table 3. $\mathrm{DM}, \mathrm{pH}$ and $\mathrm{NH}_{3}$ nitrogen $\left(\mathrm{N}-\mathrm{NH}_{3}\right)$ concentration in digesta from different segments of the gastrointestinal tract at the day of euthanasia in pigs fed diets containing inulin and experimentally challenged with Brachyspira hyodysenteriae

(Mean values and pooled standard errors, fifteen pigs per dietary treatment)

\begin{tabular}{|c|c|c|c|c|c|c|c|c|}
\hline \multirow[b]{2}{*}{ Inulin $(\mathrm{g} / \mathrm{kg}) \ldots$} & \multirow[b]{2}{*}{0} & \multirow[b]{2}{*}{20} & \multirow[b]{2}{*}{40} & \multirow[b]{2}{*}{80} & \multirow[b]{2}{*}{ SEM } & \multicolumn{3}{|c|}{$P$} \\
\hline & & & & & & Inulin & Linear & Quadratic \\
\hline \multicolumn{9}{|l|}{ DM (\%) } \\
\hline Ileum & $12 \cdot 9$ & 11.4 & $10 \cdot 2$ & 11.9 & 0.83 & 0.160 & 0.454 & 0.035 \\
\hline Caecum & $18 \cdot 8^{a}$ & $16 \cdot 1^{a, b}$ & $13 \cdot 9^{b}$ & $13 \cdot 7^{\mathrm{b}}$ & 1.29 & 0.024 & 0.007 & 0.035 \\
\hline Upper colon & $10 \cdot 4$ & $10 \cdot 8$ & $9 \cdot 6$ & $12 \cdot 2$ & 1.23 & 0.491 & 0.307 & 0.363 \\
\hline Lower colon & $6 \cdot 4$ & $8 \cdot 2$ & $9 \cdot 1$ & $11 \cdot 7$ & 1.34 & 0.060 & 0.007 & 0.885 \\
\hline \multicolumn{9}{|l|}{$\mathrm{pH}$} \\
\hline Ileum & $7 \cdot 3$ & $7 \cdot 3$ & $6 \cdot 9$ & $7 \cdot 2$ & 0.13 & 0.112 & 0.496 & 0.094 \\
\hline Caecum & $6 \cdot 7$ & $6 \cdot 6$ & $6 \cdot 4$ & $6 \cdot 3$ & 0.18 & 0.311 & 0.072 & 0.755 \\
\hline Upper colon & $6 \cdot 6$ & $6 \cdot 7$ & $6 \cdot 6$ & $6 \cdot 4$ & 0.12 & 0.174 & 0.047 & 0.411 \\
\hline Lower colon & $7 \cdot 0$ & $6 \cdot 9$ & $7 \cdot 0$ & $6 \cdot 9$ & $0 \cdot 10$ & 0.972 & 0.735 & 0.953 \\
\hline \multicolumn{9}{|l|}{$\mathrm{N}-\mathrm{NH}_{3}(\mathrm{mg} / \mathrm{kg})$} \\
\hline Caecum & 485 & 385 & 404 & 327 & $69 \cdot 8$ & 0.432 & 0.131 & 0.768 \\
\hline Upper colon & 556 & 522 & 690 & 413 & $76 \cdot 6$ & 0.085 & 0.237 & 0.086 \\
\hline Lower colon & 531 & 502 & 520 & 485 & $48 \cdot 4$ & 0.911 & 0.554 & 0.962 \\
\hline
\end{tabular}

${ }^{a, b}$ Mean values with unlike superscript letters were significantly different $(P<0.05)$.

$P=0.039$ ), caecum (Pearson's $r=-0.55 ; P<0.001$ ), upper colon (Pearson's $r=-0.69 ; P<0.001$ ) and lower colon (Pearson's $r=-0.58 ; P<0.001$ ).

\section{Ileal histology and pig performance}

Ileal villus height, crypt depth and the villus:crypt ratio were unaffected by the dietary treatments (data not shown). Average daily gain did not differ in the 2 -week adaptation period before pigs were challenged with B. byodysenteriae. The pigs fed diets containing $0,20,40$ and $80 \mathrm{~g} / \mathrm{kg}$ inulin grew on average 660 (SEM 43.0), 753 (SEM 46.8), 752 (SEM 45.1) and 661 (SEM 43.4) g/d, respectively. Overall, pig performance was unaffected by the dietary inclusion rates of inulin.

\section{Discussion}

The model of SD used in the present study was effective, as all fifteen pigs fed the control diet developed disease. In this setting, $80 \mathrm{~g} / \mathrm{kg}$ dietary inulin inhibited the development of SD, confirming our previous findings ${ }^{(7)}$. However, lower concentrations of inulin were not protective, demonstrating that a high concentration of dietary inulin is required for protection if it is used as the sole intervention. In the present study, more than half of the pigs (eight out of fifteen pigs) fed $80 \mathrm{~g} / \mathrm{kg}$ inulin developed the disease, whereas disease occurred only in $15 \%$ of the pigs (three out of twenty pigs) receiving this concentration of inulin in our previous study ${ }^{(7)}$. This difference might be explained by the amount and concentration of the broth used to challenge the pigs: in the present study, the pigs were challenged on four consecutive days with $100 \mathrm{ml}$ of a broth containing approximately $10^{9}$ colonyforming units/ml of B. hyodysenteriae compared with $80 \mathrm{ml}$ of a broth culture with approximately $10^{8}$ colony-forming units $/ \mathrm{ml}$ viable cells in the previous study ${ }^{(7)}$. With this regard, a higher level of infectious challenge may have overwhelmed the protection afforded by the inulin.
Nonetheless, the present findings are in accordance with other researchers who also found that fermentable dietary carbohydrates reduced the incidence of $\mathrm{SD}^{(6,21)}$. In a field study, Bilic \& Bilkie ${ }^{(21)}$ observed that a diet with wheat shorts and maize starch reduced the incidence of SD but, as in the present study, total protection against SD was not achieved. In contrast, Thomsen et al. ${ }^{(6)}$ found that an organic diet based on dried chicory roots and lupins completely protected pigs against SD after experimental challenge with B. byodysenteriae. In our previous study, we demonstrated that pigs fed $80 \mathrm{~g} / \mathrm{kg}$ inulin had a reduced risk of developing $\mathrm{SD}$, while the onset of disease was delayed in pigs fed lupins ${ }^{(7)}$; however, unlike Thomsen et $a l^{(6)}$, it was found that a small number of pigs fed the various 'protective' diets developed the disease. These discrepancies are most probably due to differences in virulence of the different strains of B. byodysenteriae employed or differences in the experimental diets used.

In contrast, feeding fermentable carbohydrates from sugarbeet pulp, wheat shorts and potato starch failed to prevent the development of $\mathrm{SD}^{(2)}$, while feeding diets that contained wheat, barley or oat groats resulted in an almost $100 \%$ incidence of $\mathrm{SD}^{(12)}$. This demonstrates that the amount and properties of the dietary carbohydrates are important considerations when formulating diets to control infections with $B$. byodysenteriae.

The present findings seemingly contradict previous findings, where diets supplemented with soluble NSP and resistant starch were associated with the development of SD compared with diets based on cooked white rice and animal proteins ${ }^{(4,5,12)}$. On the other hand, attempts to reproduce these results by Lindecrona et $a l .{ }^{(3)}$ and Kirkwood et al. ${ }^{(2)}$ failed, which again could be due to the difference in the experimental designs such as differences in rice processing or virulence of the strains of B. byodysenteriae ${ }^{(22)}$.

Fermentation of inulin by the indigenous microbiota results in the production of VFA and gases ${ }^{(9)}$, so consequently the 
Table 4. Total volatile fatty acid (VFA) concentration (mmol/kg of digesta) and molar proportion of the organic acids in digesta from different segments of the gastrointestinal tract at the day of euthanasia in pigs fed diets containing inulin and experimentally challenged with Brachyspira hyodysenteriae

(Mean values and pooled standard errors, fifteen pigs per dietary treatment)

\begin{tabular}{|c|c|c|c|c|c|c|c|c|}
\hline \multirow[b]{2}{*}{ Inulin $(g / k g) \ldots$} & \multirow[b]{2}{*}{0} & \multirow[b]{2}{*}{20} & \multirow[b]{2}{*}{40} & \multirow[b]{2}{*}{80} & \multirow[b]{2}{*}{ SEM } & \multicolumn{3}{|c|}{$P$} \\
\hline & & & & & & Inulin & Linear & Quadratic \\
\hline \multicolumn{9}{|l|}{ Ileum } \\
\hline Total VFA+lactic acid (mmol/kg) & $29 \cdot 0$ & 31.9 & 33.0 & $35 \cdot 4$ & $4 \cdot 7$ & 0.793 & 0.318 & 0.839 \\
\hline Lactic acid (\%) & $50 \cdot 8$ & $53 \cdot 0$ & $60 \cdot 8$ & 53.9 & $7 \cdot 1$ & 0.770 & 0.703 & 0.401 \\
\hline Acetic acid (\%) & $36 \cdot 0$ & $39 \cdot 3$ & 31.3 & $40 \cdot 1$ & 5.4 & 0.655 & 0.712 & 0.511 \\
\hline Propionic acid (\%) & $4 \cdot 3$ & $2 \cdot 6$ & 2.7 & 1.2 & $1 \cdot 1$ & 0.271 & 0.060 & 0.793 \\
\hline Butyric acid (\%) & 4.9 & 2.5 & 3.4 & $3 \cdot 0$ & $1 \cdot 2$ & 0.503 & 0.396 & 0.395 \\
\hline Other VFA* $(\%)$ & 4.0 & $2 \cdot 6$ & 1.8 & 1.8 & $1 \cdot 1$ & 0.400 & 0.142 & 0.355 \\
\hline \multicolumn{9}{|l|}{ Caecum } \\
\hline Total VFA $(\mathrm{mmol} / \mathrm{kg})$ & 123.4 & $130 \cdot 0$ & 131.4 & $156 \cdot 8$ & $10 \cdot 3$ & 0.113 & 0.018 & 0.545 \\
\hline Acetic acid (\%) & $52 \cdot 6$ & 53.4 & 51.8 & 51.8 & 1.7 & 0.879 & 0.585 & 0.964 \\
\hline Propionic acid (\%) & 24.9 & $26 \cdot 0$ & $27 \cdot 1$ & $27 \cdot 3$ & 1.0 & 0.268 & 0.067 & 0.439 \\
\hline Butyric acid (\%) & $11 \cdot 6$ & $11 \cdot 7$ & 11.1 & 11.8 & 0.8 & 0.921 & 0.857 & 0.632 \\
\hline Valeric acid (\%) & 4.6 & 4.0 & 4.4 & $5 \cdot 2$ & 0.5 & 0.416 & 0.268 & 0.248 \\
\hline Caproic acid (\%) & 0.9 & 0.9 & 1.0 & 0.8 & 0.1 & 0.814 & 0.546 & 0.610 \\
\hline Isobutyric acid (\%) & $2 \cdot 2$ & 1.7 & 1.9 & $1 \cdot 2$ & 0.3 & 0.067 & 0.015 & 0.766 \\
\hline Isovaleric acid (\%) & $3 \cdot 2$ & $2 \cdot 3$ & $2 \cdot 7$ & 1.8 & 0.4 & 0.069 & 0.026 & 0.959 \\
\hline \multicolumn{9}{|l|}{ Upper colon } \\
\hline Total VFA $(\mathrm{mmol} / \mathrm{kg})$ & $107 \cdot 0^{\mathrm{a}}$ & $110 \cdot 6^{\mathrm{a}}$ & $113 \cdot 9^{a}$ & $133 \cdot 1^{\mathrm{b}}$ & $5 \cdot 8$ & 0.012 & 0.001 & 0.389 \\
\hline Acetic acid (\%) & 53.7 & 54.0 & 53.1 & 50.9 & $1 \cdot 2$ & 0.272 & 0.065 & 0.493 \\
\hline Propionic acid (\%) & $24 \cdot 1$ & 24.5 & $25 \cdot 1$ & 25.9 & 0.7 & 0.236 & 0.038 & 0.967 \\
\hline Butyric acid (\%) & $10 \cdot 2$ & $10 \cdot 8$ & $10 \cdot 6$ & 11.9 & 0.7 & 0.288 & 0.070 & 0.669 \\
\hline Valeric acid (\%) & $4 \cdot 1^{\mathrm{a}}$ & $3.9^{\mathrm{a}}$ & $4 \cdot 3^{\mathrm{a}}$ & $5 \cdot 4^{\mathrm{b}}$ & 0.4 & 0.027 & 0.007 & 0.173 \\
\hline Caproic acid (\%) & 0.8 & 0.9 & 0.9 & 1.0 & $0 \cdot 1$ & 0.416 & $0 \cdot 104$ & 0.823 \\
\hline Isobutyric acid (\%) & $2 \cdot 9$ & $2 \cdot 6$ & 2.5 & $2 \cdot 0$ & 0.3 & 0.081 & 0.011 & 0.979 \\
\hline Isovaleric acid (\%) & $4 \cdot 1$ & $3 \cdot 4$ & 3.6 & $2 \cdot 8$ & 0.4 & 0.070 & 0.013 & 0.959 \\
\hline \multicolumn{9}{|l|}{ Lower colon } \\
\hline Total VFA $(\mathrm{mmol} / \mathrm{kg})$ & 79.9 & $88 \cdot 6$ & 89.8 & 99.9 & $5 \cdot 6$ & 0.093 & 0.013 & 0.832 \\
\hline Acetic acid (\%) & $55 \cdot 8$ & $55 \cdot 2$ & $55 \cdot 7$ & $54 \cdot 2$ & 1.0 & 0.654 & 0.268 & 0.707 \\
\hline Propionic acid (\%) & $24 \cdot 2$ & $23 \cdot 8$ & 23.8 & $23 \cdot 7$ & 0.6 & 0.927 & 0.540 & 0.787 \\
\hline Butyric acid (\%) & 7.9 & $9 \cdot 2$ & 9.0 & $10 \cdot 3$ & 0.7 & 0.127 & 0.026 & 0.781 \\
\hline Valeric acid (\%) & $3 \cdot 3^{\mathrm{a}}$ & $3 \cdot 4^{a}$ & $3.5^{\mathrm{a}}$ & $4 \cdot 0^{\mathrm{b}}$ & 0.2 & 0.039 & 0.005 & 0.510 \\
\hline Caproic acid (\%) & 0.9 & 1.0 & 0.9 & 1.1 & $0 \cdot 1$ & 0.119 & 0.051 & 0.747 \\
\hline Isobutyric acid (\%) & 3.5 & $3 \cdot 2$ & 3.0 & $2 \cdot 8$ & 0.2 & 0.275 & 0.056 & 0.632 \\
\hline Isovaleric acid (\%) & 4.5 & $4 \cdot 1$ & 4.1 & 3.8 & 0.3 & 0.475 & 0.153 & 0.655 \\
\hline
\end{tabular}

${ }^{\mathrm{a}, \mathrm{b}}$ Mean values with unlike superscript letters were significantly different $(P<0.05)$.

* Sum of butyric, valeric, caproic, isobutyric, isovaleric and succinic acid.

luminal $\mathrm{pH}$ values in the caecum and upper colon decreased with increasing levels of dietary inulin. Similarly, the concentration of VFA in the caecum, upper colon and lower colon increased when pigs were fed higher concentrations of inulin. Generally, dietary inclusion of inulin has shown contradictory results with respect to luminal $\mathrm{pH}$ values and VFA concentrations. Hansen et al. ${ }^{(7)}$ observed that feeding $80 \mathrm{~g} / \mathrm{kg}$ inulin to pigs experimentally challenged with $B$. byodysenteriae had no influence on large-intestinal $\mathrm{pH}$ values and total VFA concentrations, whereas Halas et al. ${ }^{(23)}$ using weaner pigs and Loh et $a l^{(24)}$ using grower pigs observed lower total VFA concentrations in the large intestine when diets were supplemented with inulin. Nonetheless, the negative correlations between digesta VFA concentration and luminal $\mathrm{pH}$ observed in the present study support the notion that undigested carbohydrate entering the large intestine functions as a substrate for fermentative processes which generates a higher concentration of VFA to cause a decrease in $\mathrm{pH}$.

In the present study, feeding increasing levels of inulin significantly influenced the proportion of VFA in the luminal contents, which concurs with previous findings ${ }^{(7,23,24)}$. According to Cummings \& Macfarlane ${ }^{(25)}$, dietary inulin mainly stimulates lactobacilli that produce lactic and acetic acids. However, no increase in acetic acid concentration was observed in the present study, and hence butyrate and valerate concentration should not be affected. However, Bindelle et $a l .{ }^{(26)}$ reported that in human subjects, butyrateproducing bacteria can be net utilisers of acetate to the extent that the proportion of acetate can be the reciprocal of the concentration of butyrate due to bacterial cross-feeding. Indeed, Mølbak et al. ${ }^{(27)}$ suggested that feeding inulin can cause an increase in lactate-producing bacteria, which in turn can stimulate lactate-utilising butyrate producers such as Megasphaera elsdenii.

VFA produced by the intestinal microbiota are commonly divided into straight-chain fatty acids and BCFA. Straight-chain fatty acids such as acetic, propionic and butyric acids are produced from carbohydrate fermentation, while BCFA such as isobutyric and isovaleric acids are produced by fermentation of proteins ${ }^{(28,29)}$. In addition, fermentation of protein in the 
large intestine normally becomes more evident as carbohydrate availability becomes a limiting factor for microbial fermentation $^{(30)}$. Collectively, this could explain the decline in BCFA in the caecum and colon with increasing levels of dietary inulin, as the preferential metabolism of inulin by carbohydrate-fermenting bacteria may have lessened the activity of the proteolytic bacteria. In agreement, Jensen et $a l^{(18)}$ showed that the production of protein metabolites from microbial fermentation may be reduced by inclusion of NSP.

In addition to BCFA, protein fermentation may be accompanied by an increased production of $\mathrm{NH}_{3}$, indole, phenols, amines and S-containing compounds ${ }^{(31)}$. In the present study, $\mathrm{N}-\mathrm{NH}_{3}$ was measured as a marker of protein fermentation in the large intestine, which nonetheless was unaltered by dietary inulin levels. This lack of increased luminal $\mathrm{N}-\mathrm{NH}_{3}$ concentrations in the large intestine could be a result of $\mathrm{N}$ assimilation by bacteria and/or growth of the caecal and colonic biomass possibly coupled with acidification of the largeintestinal contents, resulting in the conversion of ammonia to the less diffusible $\mathrm{NH}_{4}^{+}$ion ${ }^{(32)}$.

Collectively, the data from the present study suggest that dietary supplementation with inulin probably influenced bacterial populations in the gut, resulting in the observed changes in VFA levels and proportions. These changes may have affected the pathogenesis of SD, for example by inhibiting colonisation by the spirochaete. Different dietary effects on the expression of SD are most probably linked to diet-related changes in the intestinal microbiota ${ }^{(33)}$. Such changes could either inhibit the colonisation of B. byodysenteriae directly or inhibit any of the synergistic bacteria that have been reported to facilitate colonisation with B. byodysenteriae ${ }^{(34)}$.

\section{Conclusion}

The present study demonstrated that pigs fed $80 \mathrm{~g} / \mathrm{kg}$ inulin, but not lower concentrations, have a reduced risk of developing clinical SD after experimental challenge with $B$. byodysenteriae. These results confirm previous findings by our group ${ }^{(7)}$. In addition, the present study underlines that these relative high and expensive dietary inclusion levels are necessary to induce changes in large-intestinal fermentation characteristics. Diets supplemented with $80 \mathrm{~g} / \mathrm{kg}$ inulin may protect pigs against developing SD by modifying the microbiota in the gastrointestinal tract.

\section{Acknowledgements}

The present study was supported by the Australian Cooperative Research Centre for an Internationally Competitive Pork Industry, Roseworthy, South Australia. The authors acknowledge Dr Jan Dahl for his advice concerning the statistical analysis. Each author fully contributed to the design, experiment and interpretation of the results in the manuscript. The authors have no conflict of interest to report.

\section{References}

1. Hampson DJ, Fellström C \& Thomson JR (2006) Swine dysentery. In Diseases of Swine, pp. 785-805 [BE Straw,
JJ Zimmerman, S D'Allaire and DJ Taylor, editors]. Oxford: Blackwell Publishing.

2. Kirkwood RN, Huang SX, McFall M, et al. (2000) Dietary factors do not influence the clinical expression of swine dysentery. Swine Health Prod 8, 73-76.

3. Lindecrona RH, Jensen TK, Jensen BB, et al. (2003) The influence of diet on the development of swine dysentery upon experimental infection. Anim Sci 76, 81-87.

4. Pluske JR, Durmic Z, Pethick DW, et al. (1998) Confirmation of the role of rapidly fermentable carbohydrates in the expression of swine dysentery in pigs after experimental infection. J Nutr 128, 1737-1744.

5. Siba PM, Pethick DW \& Hampson DJ (1996) Pigs experimentally infected with Serpulina hyodysenteriae can be protected from developing swine dysentery by feeding them a highly digestible diet. Epidemiol Infect 116, 207-216.

6. Thomsen LE, Bach Knudsen KE, Jensen TK, et al. (2007) The effect of fermentable carbohydrates on experimental swine dysentery and whip worm infections in pigs. Vet Microbiol 119, 152-163.

7. Hansen CF, Phillips ND, La T, et al. (2010) Diets containing inulin but not lupins help to prevent swine dysentery in experimentally challenged pigs. J Anim Sci 88, 3327-3336.

8. Jensen BB \& Jørgensen H (1994) Effect of dietary fiber on microbial activity and microbial gas production in various regions of the gastrointestinal tract of pigs. Appl Environ Microbiol 60, 1897-1904.

9. Roberfroid MB, Van Loo JAE \& Gibson GR (1998) The bifidogenic nature of chicory inulin and its hydrolysis products. J Nutr 128, 11-19.

10. Macfarlane S \& Macfarlane GT (2003) Regulation of shortchain fatty acid production. Proc Nutr Soc 62, 67-72.

11. CSIRO (2008) Model Code of Practice for the Welfare of Animals: Pigs, 3rd ed. Collingwood, VIC: CSIRO Publishing.

12. Pluske JR, Siba PM, Pethick DW, et al. (1996) The incidence of swine dysentery in pigs can be reduced by feeding diets that limit the amount of fermentable substrate entering the large intestine. J Nutr 126, 2920-2933.

13. Kunkle RA, Harris DL \& Kinyon JM (1986) Autoclaved liquid medium for propagation of Treponema hyodysenteriae. J Clin Microbiol 24, 669-671.

14. La T, Phillips ND, Reichel MP, et al. (2004) Protection of pigs from swine dysentery by vaccination with recombinant $\mathrm{BmpB}$, a $29 \cdot 7 \mathrm{kDa}$ outer-membrane lipoprotein of Brachyspira byodysenteriae. Vet Microbiol 102, 97-109.

15. AOAC (1997) Official Methods of Analysis, 16th ed. Washington, DC: Association of Analytical Chemists.

16. Jenkinson SR \& Wingar CR (1981) Selective medium for the isolation of Treponema hyodysenteriae. Vet Rec 109, 384-385.

17. La T, Phillips ND \& Hampson DJ (2003) Development of a duplex PCR assay for detection of Brachyspira byodysenteriae and Brachyspira pilosicoli in pig feces. J Clin Microbiol 41, 3372-3375.

18. Jensen MT, Cox RP \& Jensen BB (1995) Microbial production of skatole in the hind gut of pigs given different diets and its relation to skatole deposition in backfat. Anim Sci 61, 293-304.

19. Heo JM, Kim JC, Hansen CF, et al. (2008) Effects of feeding low protein diets to piglets on plasma urea nitrogen, faecal ammonia nitrogen, the incidence of diarrhoea and performance after weaning. Arch Anim Nutr 62, 343-358.

20. Weatherburn MW (1967) Phenol-hypochlorite reaction for determination of ammonia. Anal Chem 39, 971-974. 
21. Bilic B \& Bilkei G (2003) Effect of highly fermentable dietary fiber on pig performance in a large unit, infected with endemic swine dysentery. Acta Vet (Beogr) 53, 229-238.

22. Pluske JR \& Hampson DJ (2009) Impact of the diet on digestive disorders of pigs, with special emphasis on proliferative enteropathy and swine dysentery. In Sustainable Animal Production: The Challenges and Potential Developments for Professional Farming, pp. 273-283 [A Aland and F Madec, editors]. Wageningen, The Netherlands: Wageningen Academic Publishers.

23. Halas D, Hansen CF, Hampson DJ, et al. (2009) Effect of dietary supplementation with inulin and/or benzoic acid on the incidence and severity of post-weaning diarrhoea in weaner pigs after experimental challenge with enterotoxigenic Escherichia coli. Arch Anim Nutr 63, 267-280.

24. Loh G, Eberhard M, Brunner RM, et al. (2006) Inulin alters the intestinal microbiota and short-chain fatty acid concentrations in growing pigs regardless of their basal diet. $J$ Nutr 136, 1198-1202.

25. Cummings JH \& Macfarlane GT (1991) The control and consequences of bacterial fermentation in the human colon. J Appl Bacteriol 70, 443-459.

26. Bindelle J, Leterme P \& Buldgen A (2008) Nutritional and environmental consequences of dietary fibre in pig nutrition: a review. Biotechnol Agron Soc Environ 12, 69-80.

27. Mølbak L, Thomsen LE, Jensen TK, et al. (2007) Increased amount of Bifidobacterium thermacidophilum and Megasphaera elsdenii in the colonic microbiota of pigs fed a swine dysentery preventive diet containing chicory roots and sweet lupine. J Appl Microbiol 103, 1853-1867.
28. Bauer E, Williams BA, Voigt C, et al. (2001) Microbial activities of faeces from unweaned and adult pigs, in relation to selected fermentable carbohydrates. Anim Sci 73, 313-322.

29. Macfarlane GT, Gibson GR, Beatty E, et al. (1992) Estimation of short-chain fatty acid production from protein by human intestinal bacteria based on branched-chain fatty acid measurements. FEMS Microbiol Ecol 10, 81-88.

30. Jensen BB (2001) Possible ways of modifying type and amount of products from microbial fermentaion in the gut. In Gut Environment of Pigs, pp. 181-200 [A Piva, KE Bach Knudsen and JE Lindberg, editors]. Nottingham: Nottingham University Press.

31. Heo JM, Kim JC, Hansen CF, et al. (2009) Feeding a diet with decreased protein content reduces indices of protein fermentation and the incidence of postweaning diarrhea in weaned pigs challenged with an enterotoxigenic strain of Escherichia coli. J Anim Sci 87, 2833-2843.

32. Gibson GR \& Roberfroid MB (1995) Dietary modulation of the human colonic microbiota: introducing the concept of prebiotics. J Nutr 125, 1401-1412.

33. Leser TD, Lindecrona RH, Jensen TK, et al. (2000) Changes in bacterial community structure in the colon of pigs fed different experimental diets and after infection with Brachyspira byodysenteriae. Appl Environ Microbiol 66, 3290-3296.

34. Whipp SC, Robinson IM, Harris DL, et al. (1979) Pathogenic synergism between Treponema byodysenteriae and other selected anaerobes in gnotobiotic pigs. Infect Immun 26, 1042-1047.

35. Boisen S (2001) In vitro Methods for Analysing Nutrient Digestibility - and their Implementation in Present and Future Feed Evaluation Systems for Pigs. Tjele: Danish Institute of Agricultural Sciences, Research Centre Foulum. 